\title{
O MAPA CONCEITUAL COMO RECURSO PEDAGÓGICO DE ENSINO NA DOCÊNCIA DA EDUCAÇÃO SUPERIOR
}

\author{
THE CONCEPTUAL MAP AS A PEDAGOGICAL TEACHING RESOURCE AT UNIVERSITIES \\ EL MAPA CONCEPTUAL COMO RECURSO PEDAGÓGICO DE ENSEÑANZA EN LA DOCENCIA DE LA EDUCACIÓN \\ SUPERIOR
}

MOURA, Ana Carolina de Oliveira Salgueiro de ${ }^{1}$
CICUTO, Camila Aparecida Tolentino ${ }^{2}$

\section{RESUMO}

Os mapas conceituais têm sido experienciados, de maneira mais comum, como forma dos estudantes demonstrarem suas compreensões acerca de conteúdos, temas e conceitos. Mas, e as experiências docentes com o uso dos mapas? A partir da definição e dos elementos essenciais que constituem os mapas e da teoria que fundamenta esse recurso, neste artigo são apresentados quatro modos diferentes do uso dos mapas como recurso pedagógico da docência na educação superior. Os resultados evidenciam o potencial dos mapas como formas de discussão e problematização dos conhecimentos prévios dos licenciandos, além de permitir a organização e sistematização prévia da ação pedagógica do professor.

Palavras-chave: Formação de professores. Conhecimento prévio. Planejamento do ensino. Mapas conceituais.

\section{ABSTRACT}

Concept maps have been experienced, most commonly, as a way for students to demonstrate their understanding of content, themes, and concepts. But what about teaching experiences with the use of maps? From the definition and the essential elements that make up the maps and the theory behind this resource, this article presents four different ways of using maps as a pedagogical resource in higher education teaching. The results show the potential of the maps as ways of discussing and problematizing the previous knowledge of the licenciandos, besides allowing the organization and prior systematization of the pedagogical action of the teacher.

Keywords: Teacher training. Previous knowledge. Teaching planning. Concept maps.

\section{RESUMEN}

Mapas conceptuales han sido experimentados, de manera más común, como forma de los estudiantes demostrar sus comprensiones acerca de contenidos, temas y conceptos. Pero, ¿y las experiencias docentes con el uso de mapas? A partir de la definición y de los elementos esenciales que constituyen los mapas y la teoría que fundamenta ese recurso, en este artículo se presentan cuatro modos diferentes del uso de los mapas como recurso pedagógico en la docencia de la educación superior. Los resultados evidencian su potencial como formas de discusión y problematización de los conocimientos previos de los licenciandos, y de organización y sistematización previa de la acción pedagógica del profesor.

Palabras clave: Formación de profesores. Conocimiento previo. Planificación de la enseñanza. Mapas conceptuales.

\footnotetext{
${ }^{1}$ Universidade Federal do Pampa - Unipampa - Rio Grande do Sul - Brasil.

2 Universidade Federal do Pampa - Unipampa - Rio Grande do Sul - Brasil.
} 


\section{INTRODUÇÃO}

É nítida a importância das pesquisas e do processo de ação-reflexão-ação na formação de professores. Muito se tem produzido sobre as práticas docentes na escola e sobre a aprendizagem dos licenciandos, mas e a docência do professor universitário? Por que não pensar e analisar nossas próprias práticas? Que possibilidades de aprendizagem nossas práticas pedagógicas potencializam? Tais questionamentos orientam as ações desta pesquisa que, a partir da definição e dos elementos essenciais que constituem os mapas e da teoria que fundamenta esse recurso, apresentada nesse artigo quatro modos diferentes do uso dos mapas como recurso pedagógico da docência na educação superior.

A docência da educação superior enquanto atividade complexa (ZABALZA, 2004) possui exigências cada vez maiores, requer que o profissional atue na graduação e na pós-graduação, produza conhecimento e; atue nas políticas educacionais e nos processos administrativos que envolvem a educação. De acordo com Pimenta e Anastasiou (2010, p. 196) para aqueles docentes universitários que desejam desenvolver o processo educativo com "competência e seriedade" é necessário um "[...] processo de reflexão sistemática e, portanto, de pesquisa", o qual deve ser proposto e realizado pelos próprios docentes. As autoras sugerem a pesquisa da própria prática docente, a qual conduz a uma postura aberta, flexível e de coragem de "enfrentamento da nossa ação profissional" (PIMENTA; ANASTASIOU 2010, p. 196). Para as autoras "a pesquisa como investigação de algo, lança-nos na interrogação, pede reflexão, crítica, enfrentamento com o instituído, descoberta, invenção e criação" (PIMENTA; ANASTASIOU 2010, p.200).

Libâneo (2008) apresenta proposta afim com as autoras supracitadas, quando afirma que ao invés de nos determos sobre: o que vamos fazer ou o que devemos fazer, é imprescindível pensarmos sobre aquilo que fazemos. Pimenta (2008) e Franco (2015) também corroboram com a ideia de produzirmos saberes docentes a partir da nossa própria prática e fazer da pesquisa acerca dessas práticas um instrumento da nossa formação docente. Assim se constituí a proposta de nos tornarmos docentes-pesquisadores da nossa própria prática, contribuindo para nos darmos conta das possibilidades do ensinar e do aprender; e da própria complexidade da formação para docência.

Nessa perspectiva, investigamos nesse artigo a prática docente universitária a partir de experiências com o uso de mapas conceituais. Nessa primeira seção apresentamos o contexto de produção dessa investigação. Na segunda seção trazemos a definição e os elementos essenciais que constituem os mapas conceituais e também a teoria na qual está fundamentado esse recurso pedagógico. A terceira seção apresenta a discussão central desse artigo, que se trata de pensar no uso do mapa conceitual como recurso pedagógico do ensino. A quarta seção foi organizada a fim de evidenciar os mapas conceituais como formas de discussão e problematização dos conhecimentos prévios dos licenciandos. Na quinta seção apresentamos os mapas como organização e sistematização prévia da ação pedagógica do professor. Na última seção sistematizamos as aprendizagens constituídas a partir da investigação da nossa própria prática docente e das 
contribuições do mapa conceitual como recurso pedagógico de ensino na docência da educação superior.

\section{MAPAS CONCEITUAIS E A APRENDIZAGEM SIGNIFICATIVA}

A necessidade de descrever mudanças de compreensão sobre conceitos científicos levou Joseph Novak da Cornell University em 1972 a desenvolver os mapas conceituais. Esse organizador gráfico se tornou um importante recurso para representar o conhecimento, não apenas no âmbito acadêmico, mas também coorporativo (NOVAK; CAÑAS, 2006). Os mapas conceituais são formados por conceitos, termos de ligação e setas. Os conceitos são regularidades percebidas em objetos/eventos, sendo na maioria dos casos apenas uma palavra. Contudo, algumas vezes podem ser utilizados símbolos ou até mais de uma palavra. Os termos de ligação devem apresentar verbos, o que garante que a relação entre os conceitos seja expressa de forma clara. Já as setas têm a função de indicar o sentido da leitura entre os conceitos. A combinação desses elementos dá origem as proposições, as quais são formadas pela união de dois conceitos através de um termo de ligação e uma seta (conceito — termo de ligação $\rightarrow$ conceito) (NOVAK; CAÑAS, 2010; NOVAK, 2010; NOVAK, 1990; TAVARES, 2007). Essa estrutura pode ser observada na Figura 1.

Figura 1. Mapa conceitual para exemplificar a estrutura desse organizador gráfico.

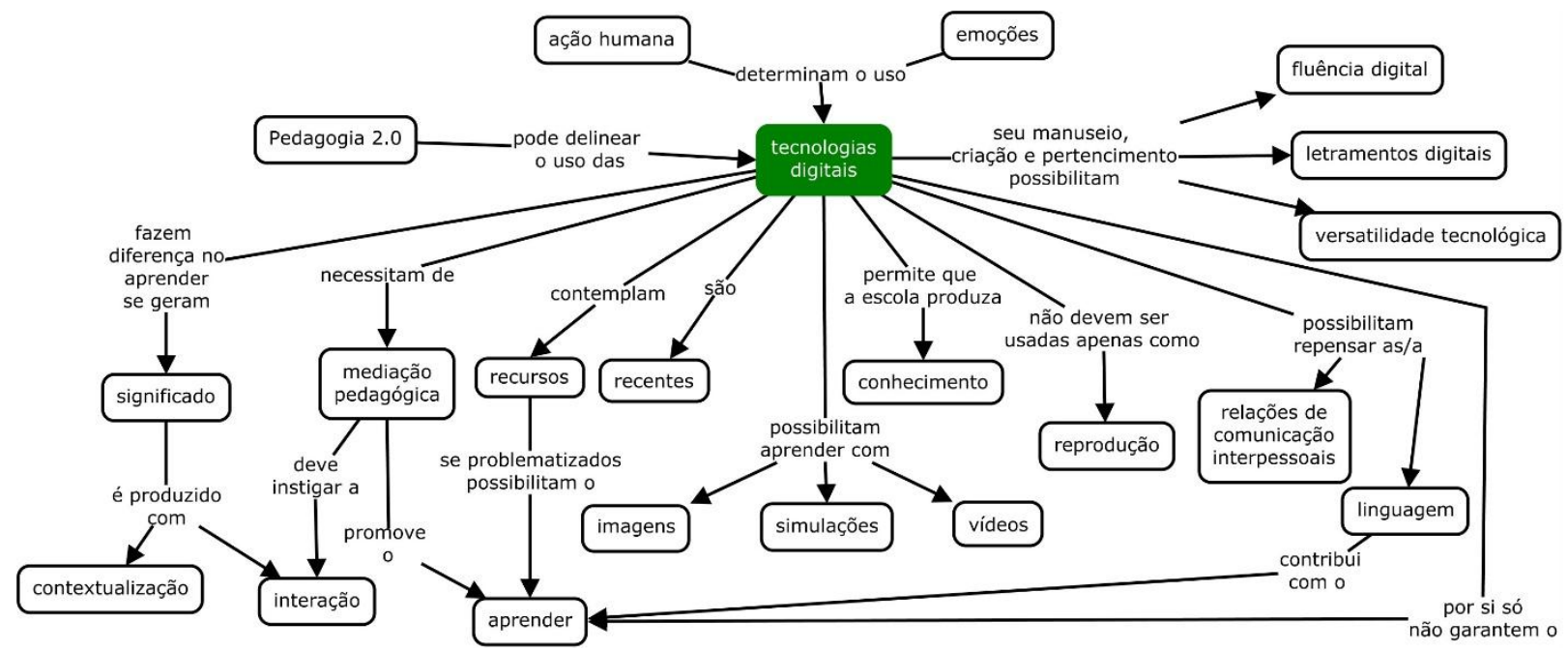

Fonte: Ana Carolina de Oliveira Salgueiro de Moura.

Novak e Cañas (2010) ao explicarem os mapas conceituais fazem uma analogia com átomos e moléculas. Os autores argumentam que os conceitos são como átomo e as proposições se assemelham as moléculas. Isso porque átomos podem ser combinados de diferentes formas resultando em um número infinito de moléculas. O mesmo se verifica nos conceitos, pois estes podem ser combinados de diferentes maneiras para a formação de proposições. Embora muitas combinações não existam, o número de possibilidades é enorme (NOVAK; CANÃS, 2010). Segundo Novak e Cañas (2010, p. 15) "enquanto as pessoas criarem e observarem objetos ou eventos novos ou pré-existentes, 
as pessoas criativas continuarão a criar novos conceitos e conhecimentos". Assim, a elaboração dos mapas conceituais contribui para estimular a criatividade e evidenciar as relações presentes na estrutura cognitiva dos indivíduos, gerando novas oportunidades de aprendizagem e de revisão de conceitos.

Esse recurso pedagógico tem como fundamentação a Teoria da Assimilação por meio da Aprendizagem e Retenção Significativas de David Ausubel (2000). Para Ausubel a aprendizagem é um continuum entre a aprendizagem mecânica e a significativa. A aprendizagem ocorre mecanicamente quando os conceitos são relacionados de maneira arbitrária e literal na estrutura cognitiva do indivíduo. Ou seja, quando não há integração entre o que o indivíduo já sabe sobre o assunto (conhecimento prévio) e a nova informação. Nesse tipo de aprendizagem acaba ocorrendo o esquecimento, uma vez que não há pontos de ancoragem na estrutura cognitiva. O oposto é verificado quando a aprendizagem ocorre de maneira significativa. Nesse caso, as relações são estabelecidas de maneira não arbitrária e não literal. $\mathrm{Na}$ aprendizagem significativa o indivíduo consegue recuperar as informações tempos depois e ainda consegue aplicar o conhecimento em diferentes contextos (AUSUBEL, 2000; MOREIRA, 2006a).

Segundo Ausubel (2000) há três tipos de aprendizagens significativas distintas: a aprendizagem representacional, a aprendizagem de conceitos e de proposições verbais. A aprendizagem representacional é mais próxima da aprendizagem mecânica. Esse tipo de aprendizagem ocorre quando símbolos arbitrários são relacionados a seus referentes objetos, eventos, conceitos. Essa aprendizagem pode ser considerada significativa, se a equivalência representacional estabelecida for relacionada de maneira não arbitrária. A aprendizagem de conceitos (objetos, eventos, situações ou propriedades) é um elemento muito importante na Teoria de Ausubel, uma vez que a aprendizagem significativa depende a disponibilidade dos conceitos presentes na estrutura cognitiva dos indivíduos (superordenados ou subordinados) na aquisição de novos conhecimentos. Por fim, a aprendizagem significativa de proposições verbais, é mais complexa do que as demais. Esse tipo de aprendizagem significativa envolve uma ideia expressa em uma frase com palavras denotativas e conotativas (AUSUBEL, 2000). Sobre este aspecto Novak e Canãs (2010) argumentam que:

A ideia fundamental na psicologia cognitiva de Ausubel é que a aprendizagem se dá por meio da assimilação de novos conceitos e proposições dentro de conceitos preexistentes e sistemas proposicionais já possuídos pelo aprendiz. Essa estrutura de conhecimento de um determinado aprendiz é também chamada de estrutura cognitiva do indivíduo [...]. (NOVAK; CANÃS, 2010, p. 11).

A partir das descrições apresentadas sobre a Teoria da Assimilação através da Aprendizagem e Retenção Significativas de Ausubel e os mapas conceituais, fica evidente o potencial desse recurso pedagógico para promover a aprendizagem significativa.

Assim, se pretendemos um novo modelo de ensino superior em que o aluno seja sujeito e construtor de sua aprendizagem e que visualize a atividade dialógica como produtora de conhecimento, a proposta da utilização de mapas conceituais representa uma estratégia 
pedagógica que possibilita a criação de um ensino significativo, estabelecendo-se um novo tipo de pensamento operacional dependente das relações cognitivas e afetivas entre os participantes do processo de ensino-aprendizagem pela criação de espaços de constantes interlocuções qualitativas. (CARABETTA JÚNIOR, 2013, p.446).

Esse potencial para promover a aprendizagem significativa é verificado, pois as aprendizagens representacionais, de conceitos e de proposições verbais podem ser externalizadas através dos mapas conceituais, visto que esse organizador gráfico permite representar graficamente as idiossincrasias dos indivíduos. Ou seja, os conceitos e proposições presentes na estrutura cognitiva dos indivíduos (interna) podem ser expressos através dos mapas (externo) com a mesma estrutura. Esses argumentos justificam a utilização dos mapas conceituais como recurso pedagógico em sala de aula.

\section{OS MAPAS NA DOCÊNCIA}

A proposição do uso dos mapas como recurso pedagógico, tem sido experienciada, de maneira mais comum, como forma de os estudantes demonstrarem suas compreensões acerca de conteúdos, temas e conceitos (STRUCHINER; VIEIRA; RICCIARDI, 1999; ALMEIDA; MOREIRA, 2008). Mas, e as experiências docentes com o uso dos mapas conceituais? Por que o professor não se desafiar a elaborar mapas para promover o diálogo, a mediação pedagógica, a síntese e problematização? No presente artigo, deslocamos o eixo do aprender para o ensinar, ainda que esse deslocamento tenha por objetivo a aprendizagem dos estudantes. O mapa conceitual como recurso pedagógico de ensino e não apenas de aprendizagem possibilita identificar os conhecimentos prévios dos alunos, ou ainda evidenciar as relações que estão sendo discutidas em sala de aula. A partir dessa estratégia é possível apresentar relações de subordinação e superordenação que irão subsidiar a aprendizagem de novos conceitos, e assim possivelmente favorecer a aprendizagem significativa (MOREIRA, 2006b). Para Carabetta Júnior (2013, p.446):

A prioridade, no ensino superior, de reproduzir conhecimentos já elaborados ao invés de buscar e estruturar novos conhecimentos resulta de uma inércia no exercício da crítica epistemológica, e essa mesma inércia que privilegia comportamentos reprodutivistas em detrimento da busca da reconstrução metodológica contínua.

Em um viés oposto ao explicitado pelo autor, buscamos investigar experiências com o uso do mapa conceitual no ensino a fim de contribuir com a reconstrução metodológica da docência na educação superior. Nesse artigo trazemos quatro modos diferentes do uso dos mapas conceituais como recurso pedagógico de ensino na educação superior, a partir de nossas experiências em cursos de licenciatura. Os mapas foram produzidos nos componentes curriculares de Organização do Trabalho Pedagógico: Didática e Formação de Professores; Educação Ambiental e Cidadania para o Campo; Tecnologias Digitais e Produção de Materiais; e Prática Pedagógica em Educação do Campo Vl: Gestão de Práticas Sustentáveis no/do Campo. Nas próximas seções foram apresentados os mapas elaborados e os processos pedagógicos associados aos mesmos. Os dois primeiros mapas 
conceituais apresentados estão baseados nos conhecimentos prévios dos licenciandos, e os dois últimos são mapas elaborados pelos docentes a fim de sistematizar e organizar os conceitos a serem desenvolvidos nos componentes curriculares.

Como caminho metodológico optamos pela metodologia qualitativa, que busca compreender os sentidos e significados de determinado fenômeno (MINAYO, 2012), no caso o fenômeno é o ensino por meio de mapas conceituais. A partir das experiências desenvolvidas foram produzidos relatos reflexivos, os quais articulados as teorias de aprendizagem compõem a análise dessas experiências. Produzir pesquisa é um modo de explicar um fenômeno, uma experiência e "explicar é sempre propor uma reformulação da experiência a ser explicada" (MATURANA, 2002, p.40). Para Maturana (2001, p.28) "[...] nem toda reformulação da experiência é uma explicação. Uma explicação é uma reformulação da experiência aceita por um observador". Ou seja, para explicação científica de um fenômeno é preciso que essa compreensão do fenômeno seja validada por outras pessoas (observadores), as quais compartilham o mesmo critério de validação (MATURANA; VARELA, 1995; MATURANA, 2001).

\section{OS MAPAS COMO FORMAS DE DISCUSSÃO E PROBLEMATIZAÇÃO DOS CONHECIMENTOS PRÉVIOS DOS ESTUDANTES}

Nessa seção apresentaremos mapas conceituais elaborados a partir de conceitos e concepções dos licenciandos acerca de abordagens vinculadas a dois componentes curriculares: "Organização do Trabalho Pedagógico - Didática e Formação de Professores" e "Educação Ambiental de Cidadania para o Campo". Tais mapas foram elaborados como representações gráficas para discussão e problematização dos conhecimentos prévios dos licenciandos.

\section{MAPA CONCEITUAL PRODUZIDO NO COMPONENTE CURRICULAR: ORGANIZAÇÃO DO TRABALHO PEDAGÓGICO - DIDÁTICA E FORMAÇÃO DE PROFESSORES}

Apresentamos a seguir o processo de produção de mapas conceituais como recurso pedagógico do componente curricular Organização do Trabalho Pedagógico - Didática e Formação de Professores. Essa experiência foi desenvolvida com uma turma de licenciandos em Educação do Campo que cursava o quinto semestre e que já possuía experiência e conhecimento na elaboração de mapas conceituais. É importante destacar essa habilidade prévia, pois foi a partir de mapas construídos individualmente, que a docente produziu mapas coletivos acerca de determinados conceitos.

Na primeira aula foi realizada uma proposta para identificação dos conhecimentos prévios dos licenciandos acerca de conceitos-chave para o componente, a saber: didática, avaliação, ensinar e aprender. A dinâmica consistiu na produção de mapas conceituais individuais, de uma maneira diferente do usual. Todos receberam uma folha em branco e foram orientados a colocar nessa folha os conceitos "didática", "avaliação", "ensinar" e "aprender" (um de cada vez) e um conceito que relacionasse com o conceito mencionado (a primeira palavra que lhes viesse à mente em relação aos 
conceitos fornecidos). Isso foi feito para cada um dos conceitos. A ideia dessa primeira parte da elaboração dos mapas individuais dos conhecimentos prévios foi de que, justamente deixassem emergir compreensões, memórias e emoções acerca de conceitos fundamentais para o desenvolvimento do componente. Com os conceitos-chave e as palavras relacionadas a esses, os licenciandos foram desafiados a construir um mapa conceitual, ou seja, apresentar que outras relações haviam entre os conceitos indicados pela docente e os conceitos que haviam incluído. Assim, os acadêmicos foram desafiados a criar proposições e dar sentido às suas concepções e aos seus entendimentos.

Os mapas individuais foram recolhidos e a docente sistematizou os mapas conceituais a partir dos conceitos-chave. Ou seja, de cada mapa singular, a docente fez um processo de sistematização para produção de um mapa conceitual coletivo da turma, no qual um dos conceitos-chave do componente curricular e as concepções associadas a esse fossem evidenciadas (Figuras 2, 3, 4 e 5). Fez isso para cada um dos conceitos e a partir dos mapas conceituais coletivos abordou nas aulas subsequentes cada um desses conceitos, trazendo teoria e referencial; problematizando e questionamento os entendimentos da turma e relacionando com diferentes experiências na educação, seja na escola ou na universidade.

Figura 2. Mapa conceitual da turma com concepções prévias sobre didática.

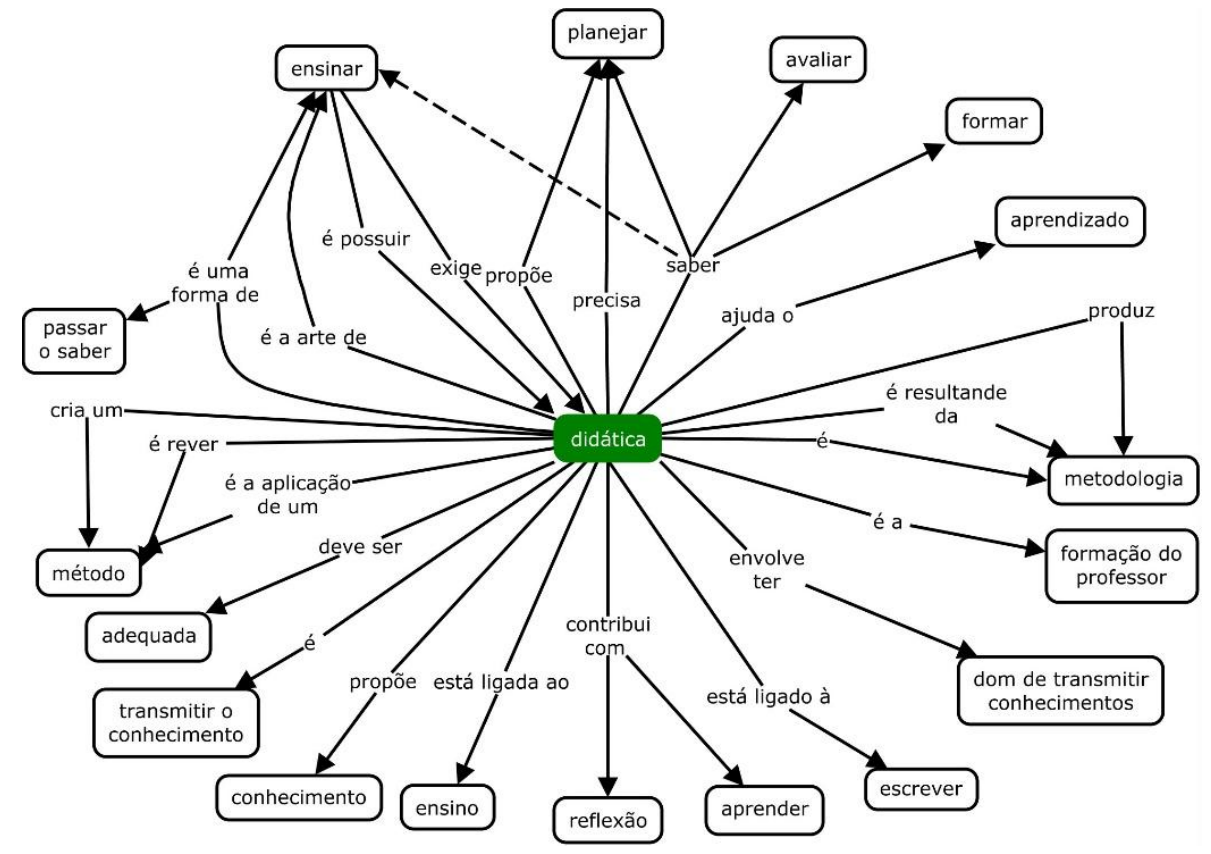

Fonte: Ana Carolina de Oliveira Salgueiro de Moura.

A partir do mapa conceitual da Figura 2 foi questionado e dabatido se ser professor depende de um dom ou se haviam saberes específicos para a formação desse profissional, e o que acarreta essa concepção de que para ser professor é preciso ou basta ter um dom. As concepções da docência vinculadas ao dom "[...] não demonstram ideias que compreendem o trabalho do professor como uma profissão, por isso, aspectos técnicos, tal como a necessidade de uma formação específica, não são considerados" (SILVA; MANO, 2018, p.194). Nesse sentido, foram apresentados e dialogados que os 
saberes docentes "[...] compõem-se de uma multiplicidade de dimensões, entre as quais se evidenciam: os saberes da formação profissional; os saberes disciplinares; os saberes curriculares; e os saberes da experiência" (FRANCO, 2015, p. 609).

Outra problematização efetivada a partir do mapa conceitual elaborado foi a desconstrução da ideia de transmitir conhecimento, tão amplamente debatida nas discussões freirianas de educação bancária e libertadora, mas que ainda está presente nos discursos. Neste sentido, os mapas conceituais evidenciam-se como recursos pedagógicos que mostram de maneira gráfica e direta algumas concepções equivocadas, bem como identificam expressões e usos da linguagem que parecem inofensivos, mas que acarretam a reprodução de processos (des)educativos. Nesse mesmo sentido, foram a cada aula, sendo realizadas problematizações e discussões, pautadas em referenciais teóricos, acerca dos mapas conceituais representados nas Figuras 3, 4 e 5.

Figura 3. Mapa conceitual da turma com concepções prévias sobre aprender.

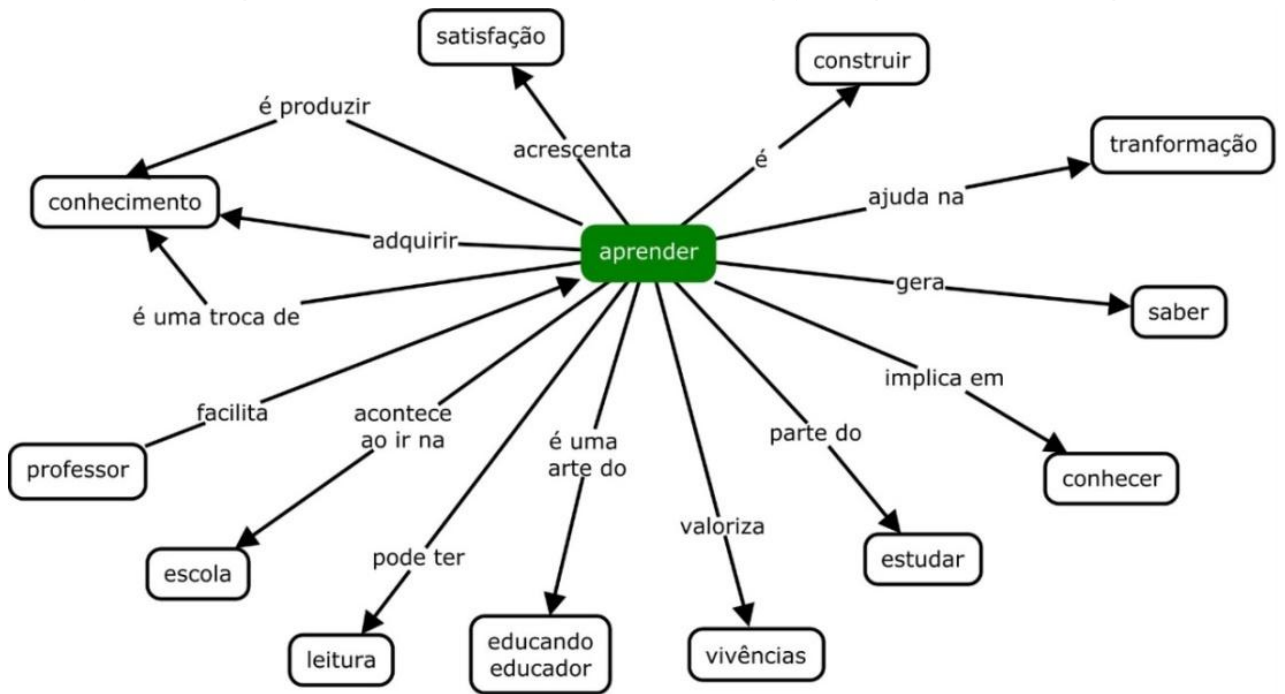

Fonte: Ana Carolina de Oliveira Salgueiro de Moura.

Figura 4. Mapa conceitual da turma com concepções prévias sobre ensinar.

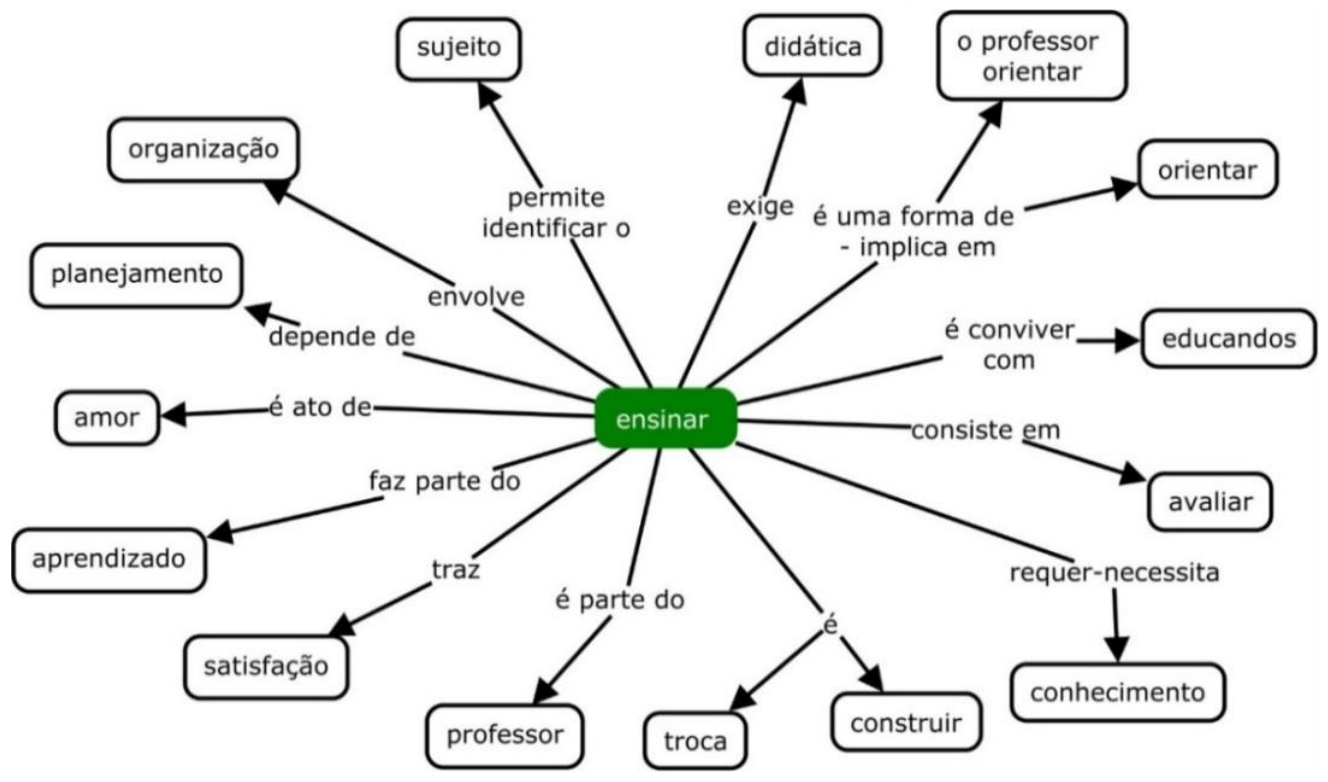

Reflexão e Ação [ISSN 1982-9949]. Santa Cruz do Sul, v. 28, n. 3, p. 231-248, set./dez. 2020. https://online.unisc.br/seer/index.php/reflex/index 
Fonte: Ana Carolina de Oliveira Salgueiro de Moura.

Figura 5: Mapa conceitual da turma com concepções prévias sobre as relações de ensinar e aprender.

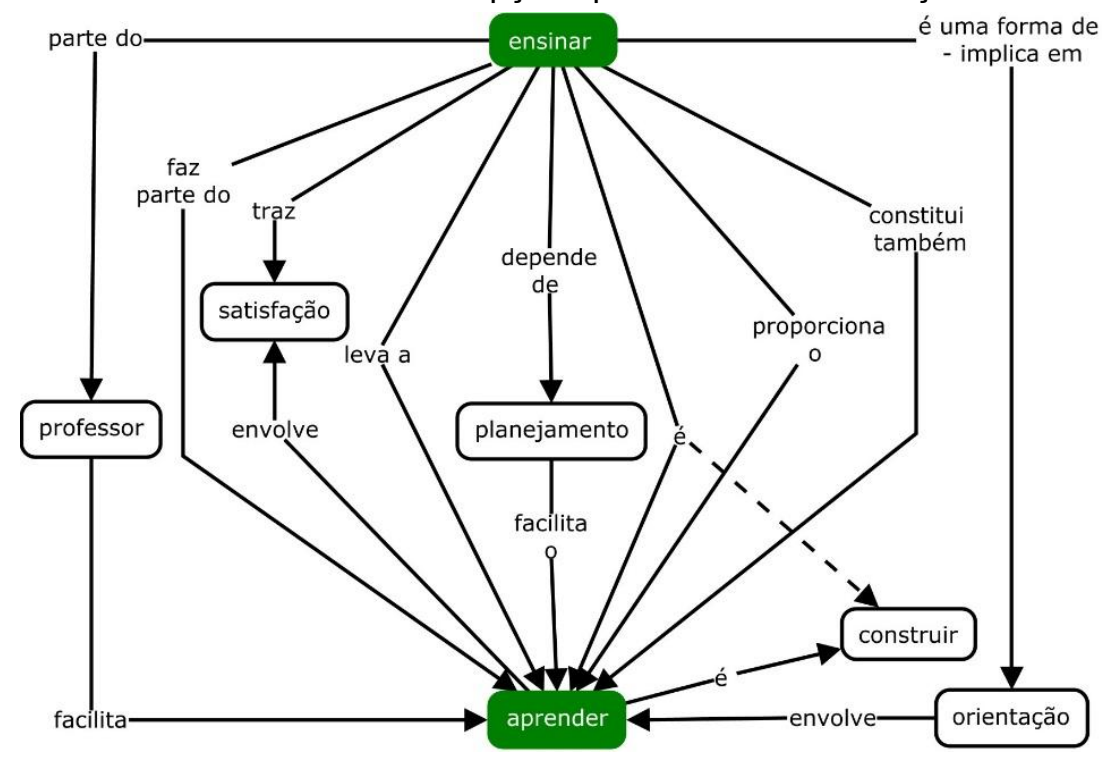

Fonte: Ana Carolina de Oliveira Salgueiro de Moura.

Conforme pode ser observado nas Figuras 2, 3, 4 e 5, os mapas elaborados possuem estrutura radial que segundo Kinchin, Hay e Adams (2000) evidenciam um baixo grau de relação entre os conceitos. Porém nesse caso, essa estrutura revela o fato de que foram compiladas diferentes concepções para o mesmo conceito. Ainda com base na observação das figuras torna-se evidente que essa estratégia pedagógica possibilita que as diferentes concepções prévias sejam "ouvidas" e consideradas, e também possibilita que tais concepções possam ser problematizadas uma a uma, sem que se constranja ou iniba a percepção do estudante. Isso porque ao apresentar o mapa da turma, não há identificação dos sujeitos e de sua concepção, o que amplia a possibilidade de discussão dessas concepções, pois se desvia de um possível julgamento da concepção de colegas e abre-se espaço para uma discussão mais aberta e focada na concepção e não em quem disse isso ou aquilo.

\section{MAPA CONCEITUAL PRODUZIDO NO COMPONENTE CURRICULAR: EDUCAÇÃO AMBIENTAL E CIDADANIA PARA CAMPO}

Diferentemente da experiência anterior, a turma na qual o mapa da Figura 6 foi elaborado ainda não conhecia os mapas conceituais. A partir do questionamento "quais as minhas experiências com Educação Ambiental?" cada estudante fez um breve relato e desse indicaram uma palavra-chave. Essas palavras foram anotadas no quadro pela docente e a partir dessas palavras e das concepções que a docente pretendia abordar, ela elaborou um mapa conceitual sobre Educação Ambiental. Para isso, as palavras-chave foram usadas como conceitos e foi se estabelecendo significado das mesmas por meio das relações e proposições elaboradas pela docente conforme mostra a Figura 6. 
Figura 6. Mapa conceitual com conceitos vinculados a Educação Ambiental, identificados pela turma e as proposições elaboradas pela docente.

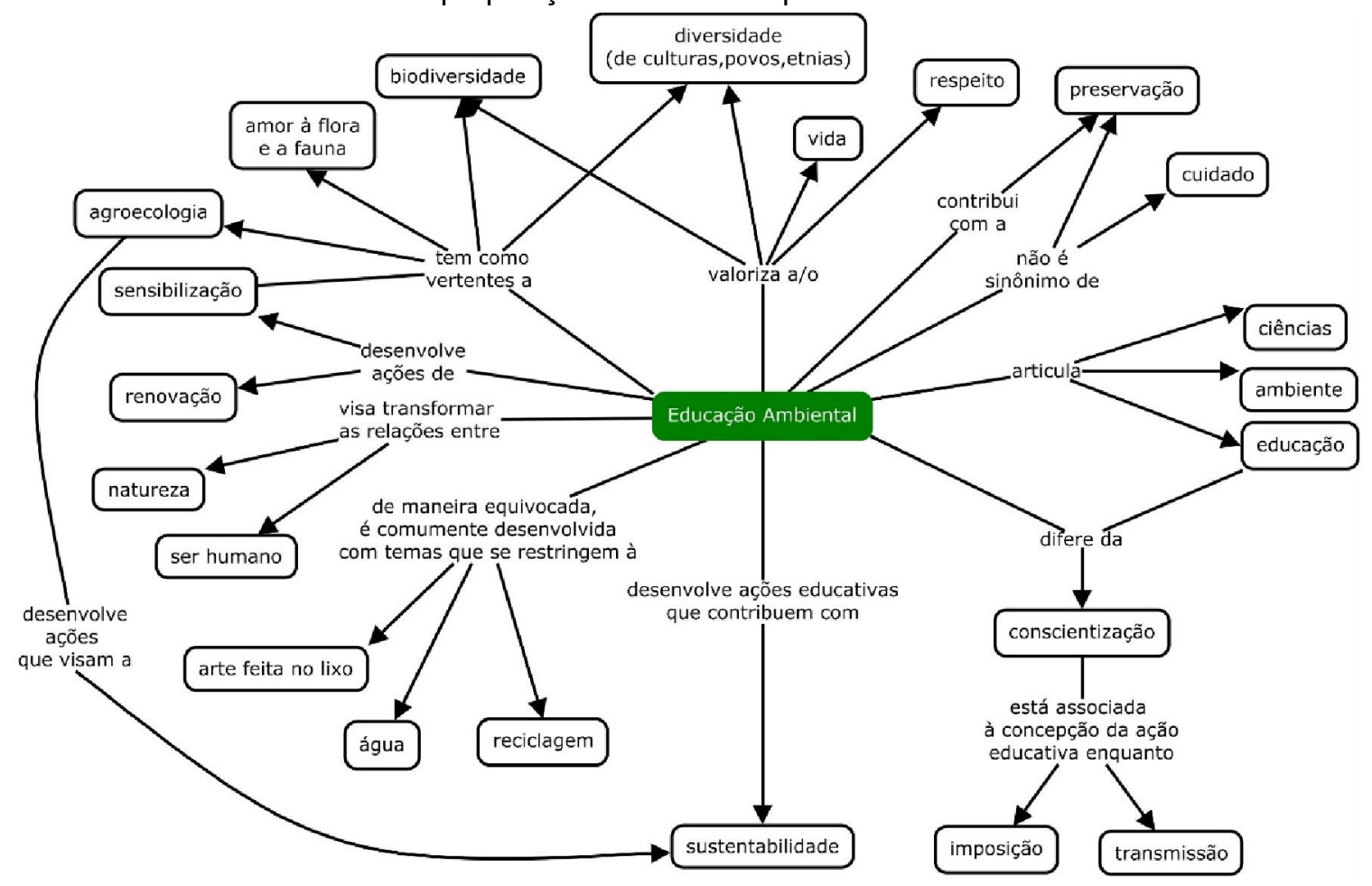

Fonte: Ana Carolina de Oliveira Salgueiro de Moura.

Nessa outra experiência com o mapa conceitual como recurso pedagógico docente, o mapa já possui estrutura mais complexa e mescla conceitos identificados pelos licenciandos e proposições propostas pelo docente. Nesse sentido o mapa elaborado já encaminha a ação, mediação e problematização pedagógica, pois as proposições anunciadas pelo docente indicam caminhos de desenvolvimento das concepções acerca de Educação Ambiental do componente. Com a elaboração desse mapa, foi possível problematizar a visão ingênua de Educação Ambiental, "[...] como se fosse uma reunião de palavras com o poder de abrir portas para um amplo e extensivo campo de consenso" (CARVALHO, 2012, p. 153). E ainda alargar a compreensão de que existem diferentes modos de compreender o conceito de meio ambiente e que, de cada uma dessas concepções deriva uma concepção de Educação Ambiental (SAUVÉ, 2005a). A partir desse campo de diversidade acerca deste conceito foram apresentadas as correntes vinculadas as diferentes proposições pedagógicas da Educação Ambiental (SAUVÉ, 2005b). A estratégia possibilitada por esse mapa conceitual e a mediação pedagógica também é expressa Carabetta Júnior (2013, p.442) quando discute sobre os mapas e a aprendizagem de conceitos na educação superior:

[...] para que a aprendizagem de conceitos seja efetiva, é necessária a conscientização do professor de que ele é o elemento responsável por conduzir o aluno na estruturação do conhecimento. E que, para isto, deve dispor de uma prática pedagógica que torne significativos os conteúdos trabalhados e que realize a interação entre o que vai ser aprendido com a estrutura cognitiva do indivíduo por um processo de assimilação entre antigos e novos significados, visando possibilitar a diferenciação cognitiva. 
Por meio desses dois mapas, foi possível identificar as concepções prévias dos licenciandos e não apenas perceber concepções ou articulações equivocadas, mas também identificar relações que não conseguiam estabelecer, ou identificar carência de complexidade nas relações entre alguns conceitos.

\section{OS MAPAS COMO ORGANIZAÇÃO E SISTEMATIZAÇÃO PRÉVIA DA AÇÃO PEDAGÓGICA DO PROFESSOR}

Nessa seção apresentaremos mapas conceituais elaborados pelas docentes, autoras desse artigo, a fim de organizar suas concepções sobre um componente, identificar conceitos fundamentais para o mesmo e relacionar esses conceitos para saber que caminhos irão trilhar no ensino. Tais mapas foram elaborados como diagramas para organizar e sistematizar previamente a ação pedagógica das professoras em dois componentes: "Tecnologias Digitais e Produção de Materiais" e "Prática Pedagógica em Educação do Campo VI: Gestão de Práticas Sustentáveis no/do Campo".

\section{MAPA CONCEITUAL PRODUZIDO NO COMPONENTE CURRICULAR: TECNOLOGIAS DIGITAIS E PRODUÇÃO DE MATERIAIS}

O mapa conceitual apresentado nessa seção buscou integrar a ementa e objetivos do componente de Tecnologias Digitais e Produção de Materiais, com os objetivos e concepções da docente. Nesse caso, vem à tona a questão de mesmo com ementa e objetivos definidos, cabe ao professor fazer o recorte e dar o foco a partir de sua formação e de suas concepções do que e de como desenvolver o processo de ensino. Esse componente traz como ementa: "Produção de material digital e pesquisa de objetos virtuais de aprendizagem das Ciências da Natureza. Análise e problematização dos objetos virtuais de aprendizagem: possibilidades de utilização e integração no processo educativo" (UNIPAMPA, 2019, p.150). Para efetivar a produção dos materiais e a análise dos objetos virtuais a docente poderia escolher diferentes caminhos. O mapa conceitual expresso na Figura 7 mostra que a proposta pedagógica da docente, nesse caso, é de que os processos de produção dos materiais digitais integrem: interação, significação e contextualização e ainda, que os mesmos contemplem imagens vídeos e simulações.

Figura 7. Mapa conceitual elaborado pela docente para sintetizar abordagens relacionadas às tecnologias digitais na educação. 


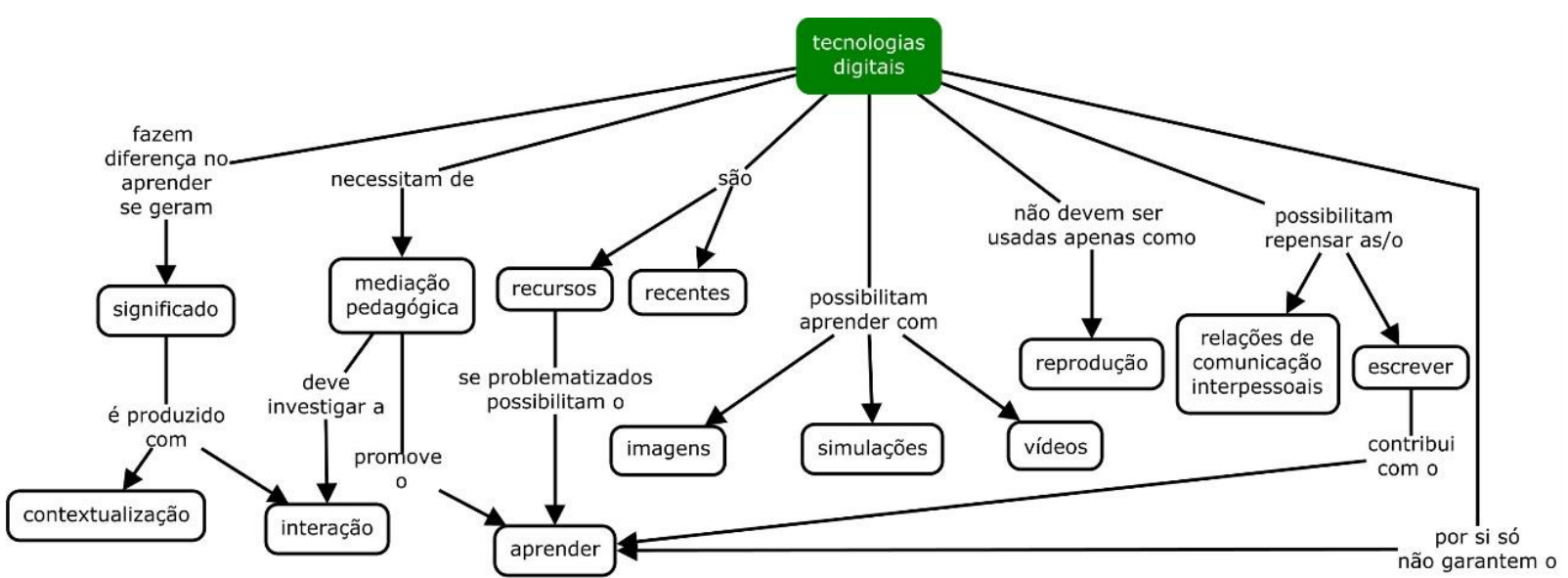

Fonte Ana Carolina de Oliveira Salgueiro de Moura.

Por meio da produção desse mapa conceitual, foi possível que a docente definisse como caminho metodológico contemplar tais relações entre conceitos, através da proposição e acompanhamento da produção de ambientes virtuais de aprendizagem, nos quais estivessem presentes os elementos técnicos e pedagógicos apresentados na Figura 7. Também por meio do mapa elaborado os discentes têm acesso à uma síntese da proposta teórico-metodológica do componente, contribuindo para que, a partir do conhecimento das bases do componente curriculares, tenham subsídios para efetivação de suas aprendizagens.

\section{MAPA CONCEITUAL PRODUZIDO NO COMPONENTE CURRICULAR: GESTÃO DE PRÁTICAS SUSTENTÁVEIS NO/DO CAMPO}

Outra experiência com o uso de mapas conceituais na docência foi quando fomos desafiadas a produzir um material didático que versasse sobre a gestão de práticas sustentáveis no/do campo. Como uma pedagoga e uma licenciada em química poderiam fazer um diálogo sobre esse tema na formação de professores? Que saberes e experiências de cada uma poderiam contribuir para o desenvolvimento do material? Partimos dos seguintes questionamentos: o que entendemos como gestão de práticas sustentáveis? E como a gestão de práticas sustentáveis no/do campo pode ser efetivada por professores? A partir desses questionamentos vinculamos os processos de gestão aos processos educativos e a questão da sustentabilidade foi articulada com a Educação Ambiental.

Então era preciso ainda pensar na ação do professor. Qual a ação do professor? Ação pedagógica que deve estar vinculada às metodologias de ensino e para complexificar mais nosso desafio, era preciso pensar no Ensino de Ciências e na Educação do Campo. Não conseguimos iniciar a produção do material didático para o componente sem antes sistematizar as relações entre conceitos previamente estabelecidos pelas temáticas (sustentabilidade, gestão de práticas sustentáveis, Educação do Campo e Ensino de Ciências). Como em nossos diálogos iniciais já havíamos pensado em propor parte do trabalho com mapas conceituais, então por que não produzirmos um mapa para organizar nossas compreensões e articulações entre os conceitos? E, além disso, afinar nosso discurso sobre o que entendemos e o que queríamos? Nesse contexto foi produzido o mapa conceitual expresso na Figura 8. 
Figura 8: Mapa conceitual elaborado pelas professoras para articular: gestão sustentável, docência,

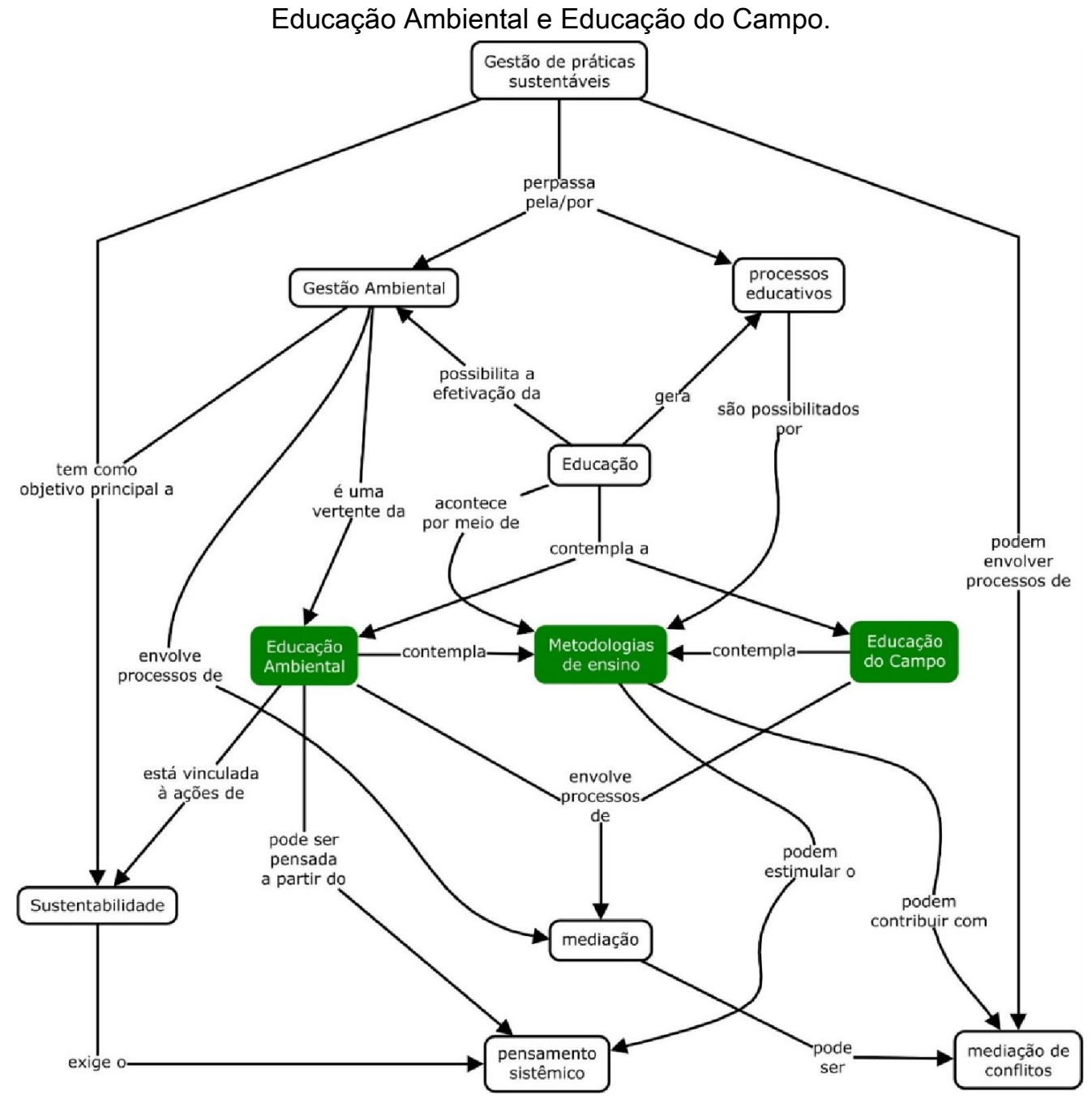

Fonte: Autora 1 e Autora 2.

Nesse mapa conceitual mostramos como articular a proposta do componente de "Gestão de Práticas Sustentáveis" de maneira a integrar a sustentabilidade, a docência, a Educação do Campo e o Ensino de Ciências. Tendo como objetivo a elaboração de um Plano de Práticas Sustentáveis no/do Campo o processo de ensino transita pelo desenvolvimento da Metodologia das Árvores (CRIVELLARO; NETO; RACHE, 2001) como estratégia de identificação de conflitos e soluções ambientais e dos mapas conceituais como recurso didático para representar de forma sistêmica os problemas ambientais e suas relações com as Ciências da Natureza. O mapa elaborado foi também referência para produção do material didático do componente (MOURA; CICUTO, 2017).

\section{CONSIDERAÇÕES FINAIS}

Fazer a investigação sobre nossa própria prática docente contribuiu com nosso processo de formação (PIMENTA; ANASTASIOU, 2010; LIBÂNEO, 2008; PIMENTA 2008; FRANCO, 2015) e com a nossa constituição como docentes-pesquisadoras, que ao nos desafiarmos a olhar e analisar o uso dos mapas como estratégia de ensino, também nos desafiamos a confrontar nossas concepções teóricas 
com seu fazer pedagógico. Foi possível perceber, que a partir das diferentes dimensões e desafios que constituem a docência na educação superior é possível abrimos espaços que oportunizam a articulação ou a problematização das concepções prévias como formas de significar as aprendizagens e complexificar o conhecimento conceitual dos estudantes. Trabalhar com a identificação de conhecimentos prévios permite que o docente conheça os estudantes e a turma e identifique caminhos para sua ação pedagógica, complexificando compreensões e preenchendo lacunas, criando problematizações e desafios que visam desestabilizar concepções de senso comum que reduzem ou minimizam a efetiva prática e formação do licenciando. De maneira análoga os mapas também se mostraram importantes recursos pedagógicos para organização pedagógica da ação docente do professor, quando possibilitam evidenciar as diferentes relações entre conceitos e abordagens a serem trabalhados em determinados componentes curriculares.

Assim, as diferentes abordagens para o uso dos mapas conceituais apresentadas neste artigo podem servir de inspiração a docentes que desejem romper com um modelo de ensino reprodutivista, que ainda prevalece no ensino superior. Contudo, oportunizar tais atividades como formas de discussão e problematização dos conhecimentos prévios e para a organização e sistematização prévia da ação pedagógica do professor exige planejamento, ou este pode resultar em frustações para o professor e alunos. E por fim, destacamos que as propostas apresentadas neste trabalho podem ser facilmente adaptadas a uma variedade de componentes e áreas do conhecimento.

\section{REFERÊNCIAS}

1. ALMEIDA, V. D. O.; MOREIRA, M. A. Mapas conceituais no auxílio à aprendizagem significativa de conceitos da óptica física. Revista Brasileira de Ensino de Física. v. 30, n. 4, 4403 (1-7), 2008. Disponível em: http://www.scielo.br/pdf/rbef/v30n4/v30n4a09. Acesso em: 17 de junho de 2019.

2. AUSUBEL, D. P. The acquisition and retention of knowledge: a cognitive view. Boston: Kluwer Academic Publishers, 2000.

3. CARABETTA JUNIOR, V. A utilização de mapas conceituais como recurso didático para a construção e inter-relação de conceitos. Revista Brasileira de Educação Médica. v. 37, n. 3, p. 441447. 2013. Disponível em: http://www.scielo.br/scielo.php?pid=S010055022013000300017\&script=sci_abstract\&tIng=pt. Acesso em:17 de junho de 2019. doi: 10.1590/S0100-55022013000300017.

4. CRIVELLARO, C. V.; NETO, M. R.; RACHE, R. P. Ondas que te quero mar: educação ambiental para comunidades costeiras - Mentalidade marítima: relato de uma experiência. Porto Alegre: Gestal/NEMA, 2001. Disponível em: http://www.nema-rs.org.br/files/publicacoes/livro.pdf. Acesso em: 30 de maio de 2019. 
5. FRANCO, M. A. S. Práticas pedagógicas de ensinar-aprender: por entre resistências e resignações. Educação Pesquisa, v. 41, n. 3. p. 601-614, 2015. Disponível em: http://www.scielo.br/pdf/ep/v41n3/1517-9702-ep-41-3-0601.pdf. Acesso em: 27 de março de 2019. doi: 10.1590/S1517-9702 201507140384.

6. KINCHIN, I. M.; HAY, D. B; ADAMS, A. How a qualitative approach to concept map analysis can be used to aid learning by illustrating patterns of conceptual development. Educational Research, v. 42, n.1, $\quad$ p. $43-57,42000.4$ Disponível https://www.tandfonline.com/doi/abs/10.1080/001318800363908. Acesso em: 17 de junho de 2019. doi: 10.1080/001318800363908.

7. LIBÂNEO, J. C. O campo teórico e profissional da didática hoje: entre Ítaca e o canto das sereias. In: EGGERT, E. (org.) Trajetórias e processos de Ensinar e aprender: didática e formação de professores: livro1. Porto Alegre, EDIPUCRS, 2008. p. 234-252.

8. MATURANA, H. R. Cognição, ciência e vida cotidiana. Belo Horizonte: UFMG, 2001.

9. MATURANA, H. R. Emoções e linguagem na educação e na política. Belo Horizonte: UFMG, 2002.

10. MATURANA, H.; VARELA, F. A árvore do conhecimento - As bases biológicas do entendimento humano. Campinas: Psy II, 1995.

11. MINAYO, M. C. de S. Análise qualitativa: teoria, passos e fidedignidade. Ciência \& Saúde Coletiva, Rio de Janeiro, v. 17, n. 3, p. 621-626, Mar. 2012. Disponível em: http://dx.doi.org/10.1590/S141381232012000300007. Acesso em: 24 out. 2019.

12. MOREIRA, M. A. A teoria da aprendizagem significativa e sua implementação em sala de aula. Brasília: Editora da UnB, 2006a.

13. MOREIRA, M. A. Mapas conceituais e diagramas V. Porto Alegre: Ed. do Autor, 2006b.

14. MOURA, A. C. O. S.; CICUTO, C. A. T. Gestão de práticas sustentáveis no/do campo. Projeto interdisciplinar do curso de Educação do Campo (Ciências da Natureza), 2017.

15. NOVAK, J. D. Concept mapping: a useful tool for science education, Journal of Research in Science Teaching, $\quad$ v. 27, $\quad$ n. 10, p. 937-949, 1990. Disponível em: https://onlinelibrary.wiley.com/doi/abs/10.1002/tea.3660271003. Acesso em: 17 de junho de 2019.

16. NOVAK, J. D. Learning, creating, and using knowledge: concept maps as facilitative tools in schools and corporations. 2.ed. Nova York: Routledge, 2010. 
17. NOVAK, J. D.; CAÑAS, A. J. A teoria subjacente aos mapas conceituais e como elaborá-los e usálos. Práxis Educativa, v.5, n.1, p. 9-29, 2010. Disponível em: http://www.revistas2.uepg.br/index.php/praxiseducativa/article/view/1298/944. Acesso em: 17 de junho de 2019. doi: 10.5212/PraxEduc.v.5i1.009029.

18. NOVAK, J. D.; CAÑAS, A. J. The origins of the concept mapping tool and the continuing evolution of the tool. Information visualization, v.5, p. 175-184, 2006. Disponível em: https://journals.sagepub.com/doi/10.1057/palgrave.ivs.9500126. Acesso em: 17 de junho de 2019.

19. PIMENTA, S. G. Epistemologia da prática ressignificando a didática. In: EGGERT, E. (ORG.) Trajetórias e processos de Ensinar e aprender: didática e formação de professores: livro1. Porto Alegre, EDIPUCRS, 2008. p. 602-625.

PIMENTA, S. G.; ANASTASIOU, L. das G. C. O docente do ensino superior. In: Docência no ensino superior. São Paulo: Cortez, 2010. p. 177-200.

SAUVÉ, L. Educação ambiental: possibilidades e limitações. Educação e Pesquisa, São Paulo, v. 31, n. 2, p. 317-322, 2005a. Disponível em: http://www.scielo.br/scielo.php?pid=S151797022005000200012\&script=sci_arttext\&tlng=es. Acesso em: 17 de junho de 2019. doi: 10.1590/S1517-97022005000200012.

SAUVÉ, L. Uma cartografia das correntes em educação ambiental. In: SATO, M; CARVALHO, I. C. M. (Org.). Educação Ambiental: pesquisa e desafio. Porto Alegre: Artmed, 2005b, p.17-44.

SILVA, E. P. da; MANO, A. de M.P. Identidade profissional docente: concepções de futuros professores. Ensino em Re-Vista. Uberlândia, MG. v. 25, n.1, p.184-208 . 2018. Disponível em: http://www.seer.ufu.br/index.php/emrevista/article/view/41365. Acesso em: 03 de maio de 2019. doi 10.14393ER-v25n1a2018-08.

STRUCHINER, M.; VIEIRA, A. R.; RICCIARDI, R. M. V. Análise do conhecimento e das concepções sobre saúde oral de alunos de odontologia: avaliação por meio de mapas conceituais. Cadernos de Saúde Pública, vol.15, suppl. 2, pp.55-68, 1999. Disponível em: http://www.scielo.br/scielo.php?pid=S0102-311X1999000600007\&script=sci_abstract\&tlng=pt. Acesso em: 03 de maio de 2019. doi 10.1590/S0102-311X199900060000.

25. TAVARES, R. Construindo mapas conceituais. Ciências \& Cognição, v.12, p.72-85, 2007. Disponível em: http://pepsic.bvsalud.org/pdf/cc/v12/v12a08.pdf. Acesso em: 03 de maio de 2019. 
26. UNIPAMPA. Projeto Pedagógico do Curso Educação do Campo - Licenciatura. UNIPAMPA, 2019.Disponível em: http://dspace.unipampa.edu.br/handle/riu/111. Acesso em: 08 de maio de 2019.

27. ZABALZA, M. A. O Ensino Universitário: seu cenário e seus protagonistas. Porto Alegre, Artmed, 2004.

\section{Ana Carolina de Oliveira Salgueiro de Moura}

Professora Adjunta na Universidade Federal do Pampa, Campus Dom Pedrito/RS. Possui Pósdoutorado em Educação em Ciências: Química da Vida e Saúde pela Universidade Federal do Rio Grande do Sul - UFRGS (2016, bolsista PNPD/CAPES). Possui Doutorado em Educação em Ciências: Química da Vida e Saúde (2015, bolsista da CAPES), mestrado em Educação Ambiental (2004) e graduação em Oceanologia (2000), todos pela Universidade Federal do Rio Grande - FURG. Licenciada em Pedagogia (2015) pela Universidade Norte do Paraná - UNOPAR. É líder do Grupo de Pesquisa Coeducar: Aprender em Ação, Metodologias de Ensino e Formação de Professores e integrante do Grupo de Pesquisa: Educação a Distância e Tecnologia - EaD-TEC (FURG). Tem experiência na área de Educação, atuando principalmente nos seguintes temas: formação de professores, metodologias de ensino, educação ambiental, tecnologias na educação, educação a distância e pesquisa.

\section{Camila Aparecida Tolentino Cicuto}

Possui doutorado em Ensino de Química pelo programa de Pós-Graduação Interunidades em Ensino de Ciências da Universidade de São Paulo (2016), mestrado em Ensino de Química pelo mesmo programa (2011) e Licenciatura em Química pela Universidade Federal de São Carlos (2007). Atualmente é professora da Universidade Federal do Pampa (Unipampa) junto ao curso de Ciências da Natureza- Licenciatura. É credenciada no Mestrado Profissional em Ensino de Ciências e Mestrado Acadêmico em Ensino atuando em pesquisas sobre metodologias de ensino, recursos didáticos, educação ambiental e produção e avaliação de material didático para o Ensino de Química/Ciências. Líder do Grupo de Pesquisa em Práticas de Ensino em Ciências (GPPEC). Membro do grupo Coeducar: Aprender em Ação, Metodologias de Ensino e Formação de Professores e do grupo Ensino de Ciências.

\section{Como citar este documento:}

MOURA, Ana Carolina de Oliveira Salgueira de; CICUTO, Camila Aparecida Tolentino. O mapa conceitual como recurso pedagógico de ensino na docência da educação superior. Reflexão e Ação, Santa Cruz do Sul, v. 28, n. 3, p. 231-248, ago. 2020. ISSN 1982-9949. Disponível em: 
<https://online.unisc.br/seer/index.php/reflex/article/view/13695>

Acesso

em:

doi:https://doi.org/10.17058/rea.v28i3.13695. 